Supplement of Hydrol. Earth Syst. Sci., 20, 4525-4545, 2016

http://www.hydrol-earth-syst-sci.net/20/4525/2016/

doi:10.5194/hess-20-4525-2016-supplement

(C) Author(s) 2016. CC Attribution 3.0 License.

(c) (1)

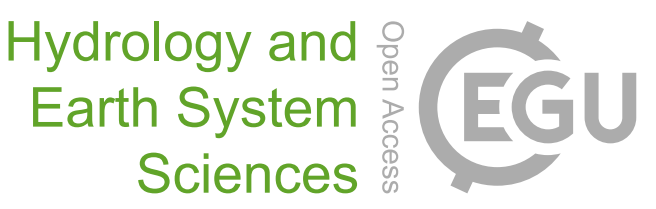

Supplement of

\title{
Multiple runoff processes and multiple thresholds control agricultural runoff generation
}

Shabnam Saffarpour et al.

Correspondence to: Andrew Western (a.western@unimelb.edu.au)

The copyright of individual parts of the supplement might differ from the CC-BY 3.0 licence. 


\section{Multiple runoff processes and multiple thresholds control agricultural runoff generation}

Shabnam Saffarpour, Andrew W. Western, Russell Adams, and Jeffrey J. McDonnell
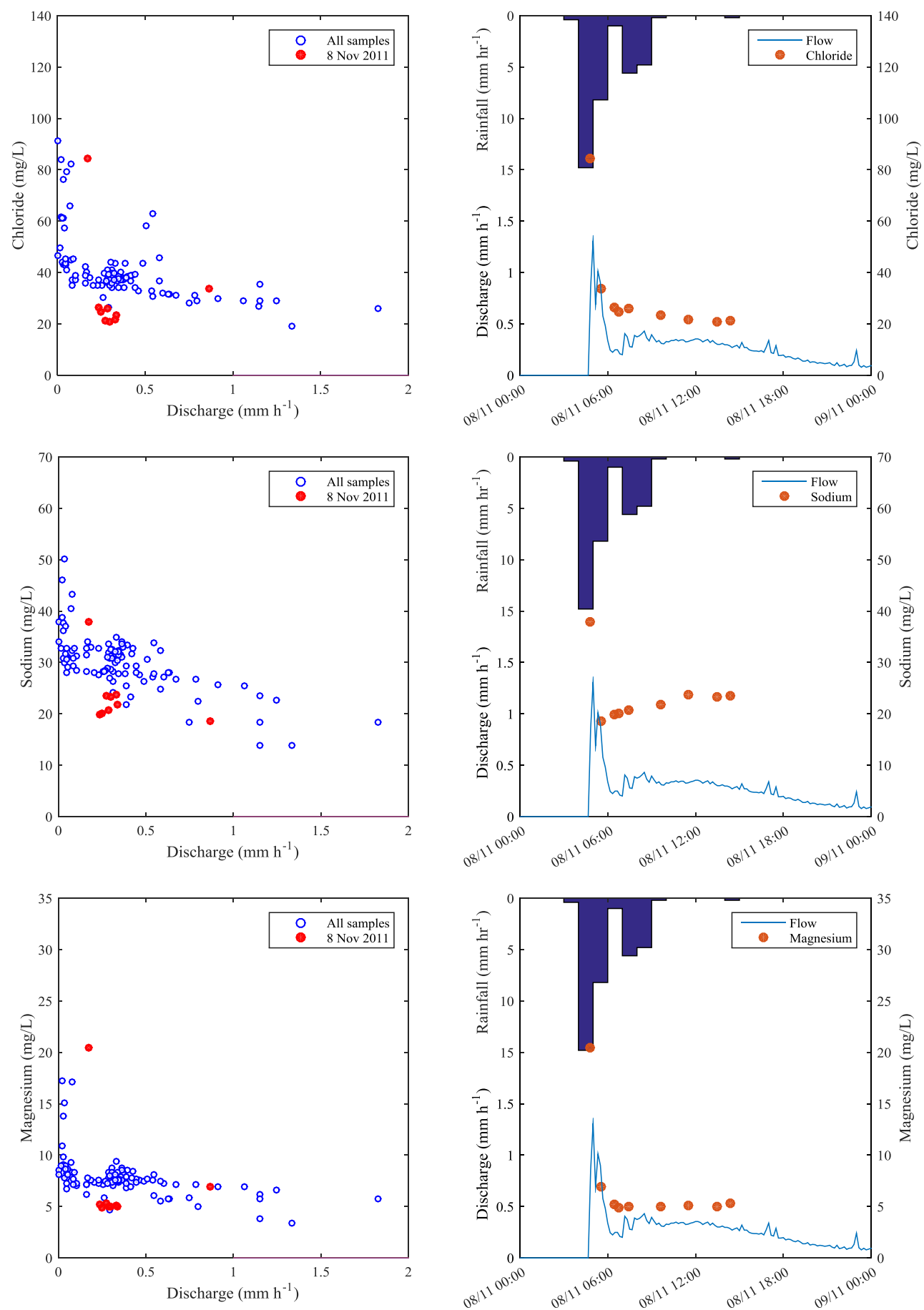

Figure S1: a) Discharge versus major ion concentration for all sampled events. The red colour identifies samples from event on $8 / 11 / 11$, and b) Time series of rainfall, runoff and concentration for the event on $8 / 11 / 11$ 

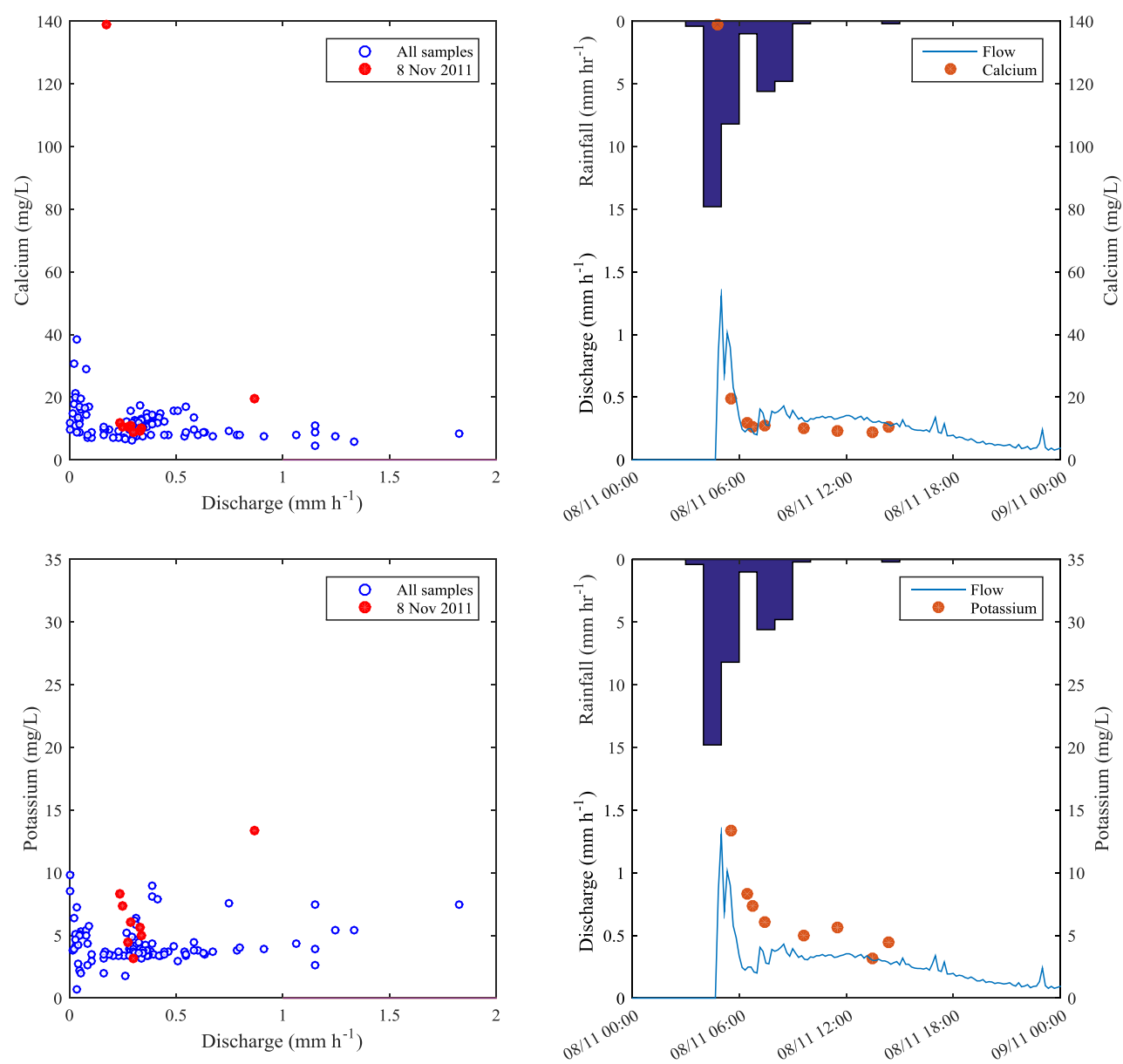

Figure S1 cont: a) Discharge versus major ion concentration for all sampled events. The red colour identifies samples from event on $8 / 11 / 11$, and b) Time series of rainfall, runoff and concentration for the event on $8 / 11 / 11$ 